JURNAL GEOGRAFI

Geografi dan Pengajarannya

ISSN 1412 - 6982

e-ISSN : 2443-3977

Volume XVIII Nomor 1 Juni 2020

\title{
ANALISA FAKTOR PENENTU LOKASI PASAR SIDOTOPO WETAN
}

\author{
Nastiti Sigra Dewi Magita \\ Program Magister Pendidikan Geografi, Sekolah Pascasarjana, UNESA \\ Jl. Lidah Wetan, Lakarsantri, Surabaya, Jawa Timur 60213
}

\begin{abstract}
Abstrak : Pasar dengan lokasi yang strategis akan mempengaruhi minat masyarakat untuk mengunjungi lokasi tersebut dalam pemenuhan kebutuhan sehari-hari. Adanya penentuan lokasi pasar bukan hanya menjadi keputusan dari pemerintah, akan tetapi juga keinginan dan pemangku kepentingan dari para pengelola dan pengguna pasar. Tujuan penelitian ini adalah untuk mengetahui lokasi Pasar Sidotopo Wetan berdasarkan hasil kajian faktor lokasi penentu pasar. Pendekatan dalam penelitian ini adalah metode theoritical analytic dan empirical analytic. Metode theoritical analytic menggunakan konstruksi teori untuk melandasi perumusan faktor-faktor pertimbangan dalam menentukan lokasi pasar berdasarkan teori-teori yang ada. Berdasarkan hasil analisis dengan menggunakan Metode Analytical Heirarchy Process dengan nilai Inconsistency 0.02, kriteria yang paling berpengaruh dalam penetuan lokasi Pasar Sidotopo Wetan adalah faktor sosial ekonomi. Kemudian yang menjadi prioritas ke dua dalam penentuan lokasi pasar tersebut adalah sarana dan prasarana yang tersedia, prioritas ketiga adalah kebijakan dan pemerintahan, serta terakhir kondisi fisik wilayah

Kata kunci : pasar, teori lokasi, sidotopo wetan
\end{abstract}

\section{A. PENDAHULUAN}

Tempat bertemunya penjual dan pembeli dalam melaksanakan proses jual beli serta adanya proses tawar menawar adalah pasar tradisional (Malano, 2011). Hasil dari adanya saling membutuhkan dalam pemenuhan kebutuhan hidup melalui proses yang melibatkan berbagai aspek adalah pasar. Pasar dapat menyebabkan adanya konsentrasi masyarakat pada beberapa waktu tertentu. Masyarakat terkonsentrasi pada waktu tertentu dapat menyebabkan penyempitan jalan yang disebabkan oleh penataan lapak dan kurangnya lahan parkir yang kurang baik. Pengelolaan kondisi pasar baik dari segi prasarana dan sarana penunjang, dan kebersihan menjadi hal penting yang menjadi pertimbangan bagi masyarakat.

Pasar ukuran skala makro merupakan salah satu sektor penunjang perekonomian sebuah kota. Pasar berpotensi dikembangkan menjadi sumber pendapatan daerah yang didapatkan melalui pajak, retribusi, dan kegiatan sektor informal dalam pasar. Lokasi ideal yang muncul dari usaha pemenuhan kebutuhan masyarakat adalah lokasi dengan aksesibitas yang mudah, praktis, dan harga yang terjangkau.

Pasar yang dimaksud dalam penelitian ini adalah Pasar Sidotopo Wetan yang dikelola oleh Kelurahan Sidotopo Wetan. Pasar tradisional 
Sidotopo Wetan memiliki fungsi yang cukup strategis dengan penjual sebagian besar berasal dari usaha kecil. Jenis perdagangan yang terjadi adalah jenis perdagangan eceran dengan menerapkan proses tawar menawar antara penjual dan pembeli. Pasar Sidotopo Wetan menjadi satu penopang perekonomian masyarakat di kelurahan Sidotopo Wetan. Pasar dimanfaatkan masyarakat dalam hal pemenuhan kebutuhan pokok. Masyarakat mengharapkan pasar yang menjual produk lengkap dengan kondisi baik dan harga yang terjangkau bagi konsumen. Keamanan lingkungan dan fasilitas parkir Pasar Sidotopo Wetan menjadi pertimbangan masyarakat. Penentuan pembangunan pasar merupakan proses yang sangat penting sebagai bentuk pengambilan keputusan masyarakat oleh pemerintah, sehingga dalam penentuan stakeholder memegang peran dan fungsi bukan hanya ditentukan oleh pihak pengembang dan pemerintah saja.

Lokasi kegiatan yang melayani kebutuhan masyarakat idealnya berada di tempat yang merupakan pusat pelayanan. Jumlah, luas dan sebaran pusat-pusat pelayanan di wilayah pemukiman juga dipengaruhi oleh jumlah penduduk yang dilayani dan jangkauan pasar dari lokasi tinggal. Pasar dengan lokasi yang strategis akan mempengaruhi minat masyarakat untuk mengunjungi lokasi tersebut dalam pemenuhan kebutuhan sehari-hari. Pasar tradisional sebaiknya didirikan pada lokasi yang ramai dan luas. Penentuan lokasi kegiatan juga mempertimbangkan aktivitas perdagangan, proses transaksi jual beli yang terjamin, keramaian lalu lintas keadaan penduduk di lingkungan pasar, keadaan parkir (Djojodipuro, 1992).

Tujuan penelitian ini adalah untuk mengetahui lokasi Pasar Sidotopo Wetan berdasarkan hasil kajian faktor lokasi penentu pasar. Manfaat penelitian ini sebagai bahan analisis mengenai lokasi Pasar Sidotopo Wetan di Kelurahan Sidotopo Wetan. Batasan masalah penelitian ini adalah analisis lokasi pasar berdasarkan kajian faktor penentu loasi pasar yang ideal.

\section{B. METODE PENELITIAN}

Pendekatan dalam penelitian ini adalah metode theoritical analytic dan empirical analytic. Metode theoritical analytic menggunakan konstruksi teori untuk melandasi perumusan faktor-faktor pertimbangan dalam menentukan lokasi pasar berdasarkan teori-teori yang ada. Metode empirical analytic mengkaitkan teori yang telah ditemukan sebagai batasan lingkup kemudian mengidentifikasi faktor empiris berdasarkan teori dan hasil analisa sebagai faktor yang juga berpengaruh dalam pertimbangan penentuan lokasi rumah pasar. 
Metode penelitian kualitatif digunakan untuk mengukur faktor penentuan lokasi pasar yang dioperasionalkan menggunakan alat analisa Analytic Hierarchy Process (AHP) untuk menentukan faktor-faktor apa saja dengan bobot tertentu yang mempengaruhi penentuan lokasi pasar (Kusrini, 2007).

Tabel 1. Variabel penelitian

\begin{tabular}{|c|c|c|}
\hline Variabel & $\begin{array}{c}\text { Sub } \\
\text { Variabel }\end{array}$ & Definisi Operasional \\
\hline \multirow[t]{2}{*}{$\begin{array}{l}\text { Kondisi } \\
\text { Fisik }\end{array}$} & $\begin{array}{l}\text { Topografi } \\
\text { datar }\end{array}$ & $\begin{array}{lc}\text { Ketinggian } & \text { tanah di } \\
\text { daerah } & \text { dibangunnya } \\
\text { pasar } & \end{array}$ \\
\hline & $\begin{array}{l}\text { Daerah tidak } \\
\text { rawan } \\
\text { bencana }\end{array}$ & $\begin{array}{l}\text { Daerah genangan yang } \\
\text { biasanya tergenang air } \\
\text { hujan saat musim } \\
\text { penghujan }\end{array}$ \\
\hline \multirow[t]{3}{*}{$\begin{array}{l}\text { Sosial- } \\
\text { ekonomi }\end{array}$} & $\begin{array}{l}\text { Kedekatan } \\
\text { dengan } \\
\text { pemukiman } \\
\text { penduduk }\end{array}$ & $\begin{array}{l}\text { Jarak pasar dengan } \\
\text { permukiman penduduk } \\
\text { yang } \\
\text { merupakan pelaku utama } \\
\text { dalam berjalannya } \\
\text { aktivitas di pasar }\end{array}$ \\
\hline & $\begin{array}{l}\text { Kepadatan } \\
\text { penduduk }\end{array}$ & $\begin{array}{l}\text { Tingkat kepadatan } \\
\text { penduduk yang } \\
\text { berpengaruh } \\
\text { terhadap banyaknya } \\
\text { pengunjung ke pasar } \\
\text { tersebut }\end{array}$ \\
\hline & $\begin{array}{l}\text { Sikap } \\
\text { masyarakat } \\
\text { terhadap } \\
\text { pembanguna } \\
\text { n pasar }\end{array}$ & $\begin{array}{l}\text { Respon yang dirasakan } \\
\text { masyarakat dengan } \\
\text { adanya } \\
\text { pembangunan pasar }\end{array}$ \\
\hline \multirow[t]{3}{*}{$\begin{array}{l}\text { Sarana dan } \\
\text { prasarana }\end{array}$} & $\begin{array}{l}\text { Ketersediaan } \\
\text { jaringan jalan } \\
\text { yang } \\
\text { memadai } \\
\text { menuju } \\
\text { lokasi pasar }\end{array}$ & $\begin{array}{l}\text { Prasarana jalan yang } \\
\text { memungkinkan } \\
\text { terjadinya } \\
\text { akses ke pasar }\end{array}$ \\
\hline & $\begin{array}{l}\text { Ketersediaan } \\
\text { pembuangan } \\
\text { limbah }\end{array}$ & $\begin{array}{l}\text { Sarana pembuangan } \\
\text { limbah sebagai tempat } \\
\text { penampungan limbah- } \\
\text { limbah dari pasar agar } \\
\text { tidak } \\
\text { menimbulkan masalah } \\
\text { kebersihan dan } \\
\text { lingkungan }\end{array}$ \\
\hline & $\begin{array}{l}\text { Ketersediaan } \\
\text { jaringan } \\
\text { listrik dan air }\end{array}$ & $\begin{array}{l}\text { Layanan kelistrikan } \\
\text { untuk memenuhi } \\
\text { kebutuhan } \\
\text { listrik di pasar. Layanan } \\
\text { air bersih untuk } \\
\text { memenuhi kebutuhan air } \\
\text { bersih di pasar. }\end{array}$ \\
\hline $\begin{array}{l}\text { Kebujakan } \\
\text { dan } \\
\text { pemerintah } \\
\text { an } \\
\end{array}$ & $\begin{array}{l}\text { Kesesuaian } \\
\text { dengan } \\
\text { Rencana Tata } \\
\text { Ruang } \\
\end{array}$ & $\begin{array}{l}\text { Rencana tata ruang } \\
\text { sebagai acuan arahan } \\
\text { pembangunan pasar }\end{array}$ \\
\hline
\end{tabular}

Teknik pengumpulan data yang digunakan adalah data primer dan sekunder. Data primer diperoleh dari pengamatan langsung atau observasi kondisi lingkungan dan perubahanperubahan yang terjadi dengan melihat dan mendengar fakta yang ada tanpa pengambilan sampel. Data sekunder diperoleh dari studi literatur yang berhubungan dengan studi yang diambil terdiri dari tinjauan teroritis. Teknik analisis data menggunakan AHP untuk memberikan bobot prioritas penentuan lokasi pasar.

\section{HASIL DAN PEMBAHASAN}

\section{C.1. HASIL}

Berdasarkan hasil analisis menggunakan teknik Analytical Heirarchy Process. Nilai Inconsistency 0,02 , didapatkan kriteria yang paling berpengaruh adalah factor sosialekonomi yaitu mempunyai bobot 0,423. Prioritas kedua dalam penentuan lokasi pasar tersebut adalah sarana dan prasarana, prioritas ketiga kebijakan dan pemerintahan, serta terakhir kondisi fisik wilayah.

Tabel 2. Bobot lokasi Pasar

\begin{tabular}{ll}
\hline \multicolumn{1}{c}{ Kriteria } & Bobot \\
\hline Sosial-Ekonomi & 0,423 \\
Sarana dan Prasarana & 0,264 \\
Kebijakan dan Pemerintahan & 0,172 \\
Kondisi Fisik & 0,141 \\
\hline
\end{tabular}

Sumber: Hasil Analisa, 2020

Faktor sosial-ekonomi merupakan faktor yang berkenaan dengan kedekatan permukiman terhadap lokasi pasar dimana penduduk merupakan pelaku 
utama dalam transaksi jual beli di Pasar Sidotopo Wetan, kepadatan penduduk mempengaruhi jumlah penduduk. yang mengunjungi pasar serta sikap yang dirasakan oleh penduduk dengan adanya pembangunan pasar. Faktor sarana dan prasarana merupakan faktor yang berkenaan dengan tersedianya moda angkutan umum yang digunakan penduduk menuju Pasar Sidotopo Wetan, tersedianya akses jalan menuju Pasar Sidotopo Wetan, tersedianya sarana pembuangan limbah, jaringan listrik, dan air bersih.

Faktor kebijakan dan pemerintahan merupakan faktor yang menjelaskan mengenai kesesuaian penggunaan lahan Pasar Sidotopo Wetan dengan arahan rencana tata ruang, dan adanya dukungan dan sumbangsih pemerintah dalam hal kesejahteraan kegiatan di pasar. Kondisi fisik merupakan faktor yang berkenaan dengan kondisi ketinggian tanah dan daerah rawan bencana di lokasi Pasar Sidotopo Wetan.

\section{C.2. PEMBAHASAN}

Lokasi pasar sebagai pusat pembelanjaan bagi masyarakat memegang peranan penting dalam percepatan pertumbuhan ekonomi di suatu daerah. Teori lokasi merupakan teori dasar yang digunakan dalam menganalisis spasial dilihat dari tata ruang dan lokasi kegiatan ekonomi (Suryani, 2015). Teori tersebut memberikan kerangka analisis dan sistematis pemilihan lokasi kegiatan ekonomi.

Teori yang mengembangkan terori lokasi sakah satunya adalah August Losch. August Losch (1954) merupakan pelopor teori lokasi Market Area dan menerbitkan tulisannya dalam sebuah buku Economic of Location. Buku tersebut menyatakan bahwa analisis pemilihan lokasi yang optimal dengan luas pasar yang dapat dikuasi dan tempat yang berkompetisi. Sangat sulit untuk menentukan satu lokasi terbaik, karena mungkin untuk mengganti kurangnya jumlah satu input (misalnya buruh) akan digantikan oleh yang lain atau meningkatnya biaya transportasi sekaligus mengurangi sewa tanah (disebut prinsip substitusi) dengan substitusi, sejumlah titik yang berbeda mungkin muncul sebagai lokasi yang optimal. Lokasi dimana saja dalam margin menjamin beberapa keuntungan.

Lokasi yang benar terletak pada wilayah yang dekat dengan bahan baku, pemukiman penduduk dan lokasi pasar sebagai tempat untuk menjual hasil produksi, sehingga laba bersihnya paling optimal. Penentuan faktor lokasi perusahaan. Perusahaan lokasinya terletak pada wilayah yang jauh dari pemukiman penduduk, karena efek negatif yang ditimbulkan dari proses pengolahan input menjadi output dapat 
dikurangi, seperti polusi, limbah, kebisingan, dan lain-lain.

Lokasi pasar biasanya dekat dengan pemukiman penduduk. Pasar memiliki lima fungsi utama. Fungsi utama adalah pasar menetapkan nilai, pasar mengorganisasikan produksi, pasar mendistribusikan barang, pasar bergungsi menyelenggarakan penjatahan, dan pasar mempertahankan serta menyediakan barang dan jasa untuk yang akan datang (Sudarman, 2011). Lokasi bahan mentah atau baku yang dibutuhkan sebagai bahan untuk diproses menjadi bahan jadi berada pada wilayah pinggiran yang jauh dari lokasi pasar. Lokasi bahan baku ini tidak selalu bisa dekat dengan lokasi perusahaan atau pabrik, dan membutuhkan sarana transportasi untuk membawa bahan mentah dari lokasinya ke pabrik untuk diolah menjadi bahan setengah jadi atau barang jadi. Ada kekuatan lain yang mengatur setiap lokasi tersebut, yaitu pemerintah. Lokasi yang memenuhi konsep tata ruang yang baik ditentukan oleh pemerintah.

Pembuatan zona metode August Losch dibuat sebagai berikut:

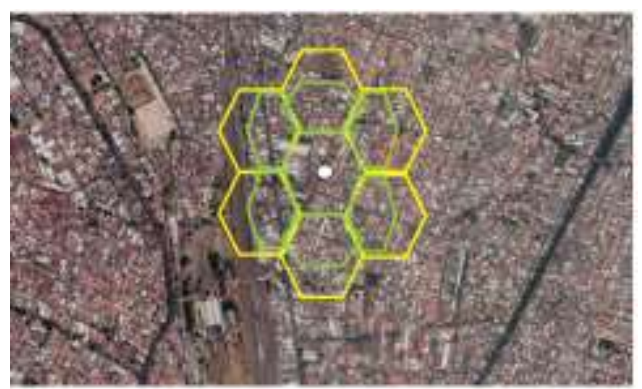

Pembangunan lokasi pasar menurut teori lokasi harus berada di kawasan yang berpengaruh $1 / 3$ penduduk dari keenam kawasan sekitar. Penunjang pembangunan lokasi perlu memperhatikan jalan beserta sarana angkutannya, tempat parkir dan barang yang diperjualbelikan.

Berdasarkan wawancara kepada pedagang Pasar Sidotopo Wetan, mengenai kondisi fisik di lokasi terbangunnya pasar tersebut didapatkan bahwa lokasi tempat dibangunnya pasar tersebut bukan merupakan daerah genangan yang memungkinkan terjadinya banjir saat musim penghujan. Genangan saat musim hujan tidak menggenang terlalu lama karena letak Pasar Sidotopo Wetan dekat dengan saluran drainase primer yaitu sungai pegirian. Sehingga, bisa dikatakan bahwa dari kriteria kondisi fisik adanya pembangunan pasar tersebut sudah sesuai.

Hasil analisa prioritas penentuan faktor yang paling mempengaruhi dari kriteria sarana dan prasarana adalah sub kriteria ketersediaan jaringan jalan yang memadai menuju lokasi pasar. Berdasarkan pengamatan lapangan didapatkan bahwa ketersediaan dan kualitas jalan menuju pasar tersebut sudah cukup baik dan lokasi pasar tersebut juga sangat strategis karena berada di dekat pusat tarikan yang sangat besar di Kota Surabaya. Dengan letaknya 
di dekat pusat kota menjamin perhatian khusus terhadap kondisi jalan. Sehingga, jika ditinjau dari segi sub kriteria ketersediaan jaringan jalan yang memadai lokasi pembangunan pasar tersebut dapat dikatakan sesuai. Ketersediaan jalan yang baik tersebut juga didukung dengan adanya angkutan umum yang melintas di pasar tersebut. Adanya alat angkutan tersebut semakin memudahkan pergerakan orang jika ingin menuju ke pasar tersebut.

Selain ketersediaan jalan, prasarana pendukung lainnya seperti adanya jaringan listrik dan air bersih juga sudah cukup baik. Namun, untuk sarana pembuangan limbah di pasar tersebut kurang tepat, karena berada di depan pasar dan terbuka. Hal tersebut menimbulkan bau yang menganggu pengguna jalan di depan pasar.

\section{KESIMPULAN}

Berdasarkan hasil analisis dengan menggunakan Metode Analytical Heirarchy Process dengan nilai Inconsistency 0.02 , kriteria yang paling berpengaruh dalam penetuan lokasi Pasar Sidotopo Wetan adalah faktor sosial ekonomi. Kemudian yang menjadi prioritas ke dua dalam penentuan lokasi pasar tersebut adalah sarana dan prasarana yang tersedia, prioritas ketiga adalah kebijakan dan pemerintahan, serta terakhir kondisi fisik wilayah.

Pasar Sidotopo Wetan menjadi salah satu penopang perekonomian masyarakat. Pasar dimanfaatkan oleh masyarakat dalam hal pemenuhan kebutuhan, khususnya kebutuhan pokok. Hasil analisafaktor penentu lokasi pasar dengan kondisi yangada dapat dikatakan lokasi pasar sudah sesuai jika ditinjau dari kriteria kondisi fisik, sosial ekonomi, sarana dan prasarana serta kebijakan dan pemerintahan.

\section{DAFTAR PUSTAKA}

Djojodipuro, M. 1992. Teori Lokasi. Lembaga Peneltian Fakultas Ekonomi Universitas Indonesia. Jakarta.

Kusrini. 2007. Konsep dan Aplikasi Sistem Pendukung Keputusan. Yogyakarta: Andi

Losch, August. 1954. Economics of Location. London

Malano, Herman. 2011. Selamatkan Pasar Tradisional. Jakarta: PT. Gramedia Pustaka Umana

Sudarman, Ari. 2011. Modul 1 Pengertian Dasar Fungsi Pasar dan Harga. Univesitas Terbuka

Suryani, Yosi. 2015. Teori Lokasi Dalam Penentuan Pembangunan Lokasi Pasar Tradisional (Telaah Studi Literatur). Seminar Nasional Ekonomi Manajemen dan Akuntansi. Fakultas Ekonomi Universitas Negeri Padang. 